\title{
42. STRONTIUM AND LEAD ISOTOPIC INVESTIGATIONS OF IGNEOUS ROCKS FROM THE MID-ATLANTIC RIDGE: DSDP, LEG 37
}

\author{
M. Yamaguchi, Department of Geology, Kyushu University, Fukuoka, Japan \\ and \\ R.L. Armstrong, Department of Geological Sciences, University of British Columbia, Vancouver, Canada \\ and
}

R.D. Russell and W.F. Slawson, Department of Geophysics and Astronomy, University of British Columbia, Vancouver, Canada

\section{INTRODUCTION}

Determinations of isotopic composition of lead and strontium in basalts and peridotite were performed on samples recovered from Holes $332 \mathrm{~A}$ and $332 \mathrm{~B}$ and Sites 334 and 335 . For five of the samples, lead concentrations were determined by isotopic dilution.

\section{ANALYTICAL PROCEDURES FOR STRONTIUM}

$\mathrm{Sr}$ isotopic compositions were measured at UBC on a $60^{\circ}$ sector, $30.5-\mathrm{cm}$ radius, solid-source mass spectrometer of a modified U.S. National Bureau of Standards design. Data produced by this system have one sigma ${ }^{87} \mathrm{Sr} /{ }^{86} \mathrm{Sr}$ errors of less than 0.0001 . All values reported are normalized and adjusted so that the Eimer and Amend Standard gives 0.70800 and the NBS standard $\mathrm{SrCO}_{3}$ (SRM 987) gives 0.71024. Samples were prepared for mass spectrometry by dissolution in HF and $\mathrm{HClO}_{4}$ and separation of $\mathrm{Sr}$ in one pass through an ion exchange column (Dowex AG 50W-X8 200-400 mesh) using $2.5 \mathrm{~N} \mathrm{HCl}$ (redistilled in silica glass). The blank for the chemical procedure is less than $0.01 \mu \mathrm{g}$. This is a negligible amount $(<0.1 \%)$ in the case of most igneous rocks, including ocean floor basalts. For ultramafic rocks containing only a few ppm of $\mathrm{Sr}$, the blank, with a ${ }^{87} \mathrm{Sr} /{ }^{86} \mathrm{Sr}$ ratio of $\sim 0.704$, may amount to $2 \%$ to $5 \%$ of the analyzed sample but the correction to the observed ${ }^{87} \mathrm{Sr} /{ }^{86} \mathrm{Sr}$ ratio would be less than 0.0001 . $\mathrm{Rb}$ and $\mathrm{Sr}$ concentrations were determined by X-ray fluorescence on pressed powder pellets. One sigma errors for concentration are $5 \%$ or $1 \mathrm{ppm}$.

\section{ANALYTICAL PROCEDURE FOR LEAD}

The samples analyzed were received in the form of fine to medium grained powders. Up to $1 \mathrm{~g}$ of sample was dissolved in a Teflon bomb using a $\mathrm{HF}-\mathrm{HNO}_{3}$ solution.

Lead was isolated in two steps by ion-exchange resin columns made of heat-shrinkable Teflon tubing with a porous hydrophilic linear polyethylene disk filter (Krogh, 1973). In the first step, a 5 to $7.5 \mathrm{~cm}, 2$ to $3 \mathrm{ml}$ resin bed (Dowex $1 \times 8, \mathrm{Cl}^{-}$form) was used. The sample solution loaded on the column was washed with 1.5 $N \mathrm{HCl}$ and the lead retained in the resin was stripped with $8 \mathrm{~N} \mathrm{HCl}$. In the second step, lead was further purified by a $2-\mathrm{cm}, 0.5-\mathrm{ml}$ resin bed (Dowex $1 \times$ $8, \mathrm{Cl}^{-}$form), washed with $1.5 \mathrm{~N} \mathrm{HCl}$ and stripped with
$0.05 \mathrm{~N} \mathrm{HCl}$. This was converted to nitrate by adding drops of concentrated $\mathrm{HNO}_{3}$. Separate samples were dissolved for unspiked and spiked lead analyses.

Reagents were purified in a subboiling still made from two Teflon bottles (Mattinson, 1972). Evaporation of the sample solution and ion exchange separation were done under a laminar flow hood to reduce contamination.

A test on basalts dredged from the Mid-Atlantic Ridge showed that recovery of lead in the chemical separation was better than $85 \%$. The blank was estimated to be several nanograms for $1 \mathrm{~g}$ of sample.

Isotopic measurements were done with a $30 \mathrm{~cm}, 90^{\circ}$ sector mass spectrometer (MS3, Geophysics, UBC) with a "Channeltron" electron multiplier as a detector and a duplex Interdata computer-controlled peak hopping system. A single filament technique was used. Lead samples were loaded onto an outgassed Re filament using silica gel and phosphoric acid.

\section{ISOTOPIC COMPOSITION}

The $\mathrm{Sr}$ isotopic compositions of the basalts, which appear reasonably fresh upon petrographic examination, are surprisingly uniform over most of the length of the long cores in Holes 332A and 332B (Figure 1). The young age of the crust in this area (approximately 3.5 m.y.), apparent freshness, and small range in isotopic composition down the core suggest that alteration of the isotopic composition of most samples is minor and that the magma had an initial ${ }^{87} \mathrm{Sr} /{ }^{86} \mathrm{Sr}$ ratio of about 0.70305 . This is distinctly higher than average ocean floor basalt but not outside the spectrum of observed values (Tatsumoto et al., 1965; Hedge and Peterman, 1970; Peterman and Hedge, 1971; Hart, 1972; Hart et al., 1973; Subbarao, 1972; Subbarao and Hedge, 1973; Dasch et al., 1973).

As can be seen from Figure 1, a few of the basaltic rocks and the one peridotite analyzed are significantly enriched in radiogenic Sr. All samples with ${ }^{87} \mathrm{Sr} /{ }^{86} \mathrm{Sr}$ greater than 0.7031 have probably reacted with seawater or brines containing radiogenic strontium, and this is particularly evident in the older rocks, those low in strontium, and those near the sea floor. Such alteration has been noted previously (Hart and Nalwalk, 1970; Dasch et al., 1973; Hart, 1973). The high ratio obtained for a partially serpentinized peridotite is consistent with the higher ratios reported 


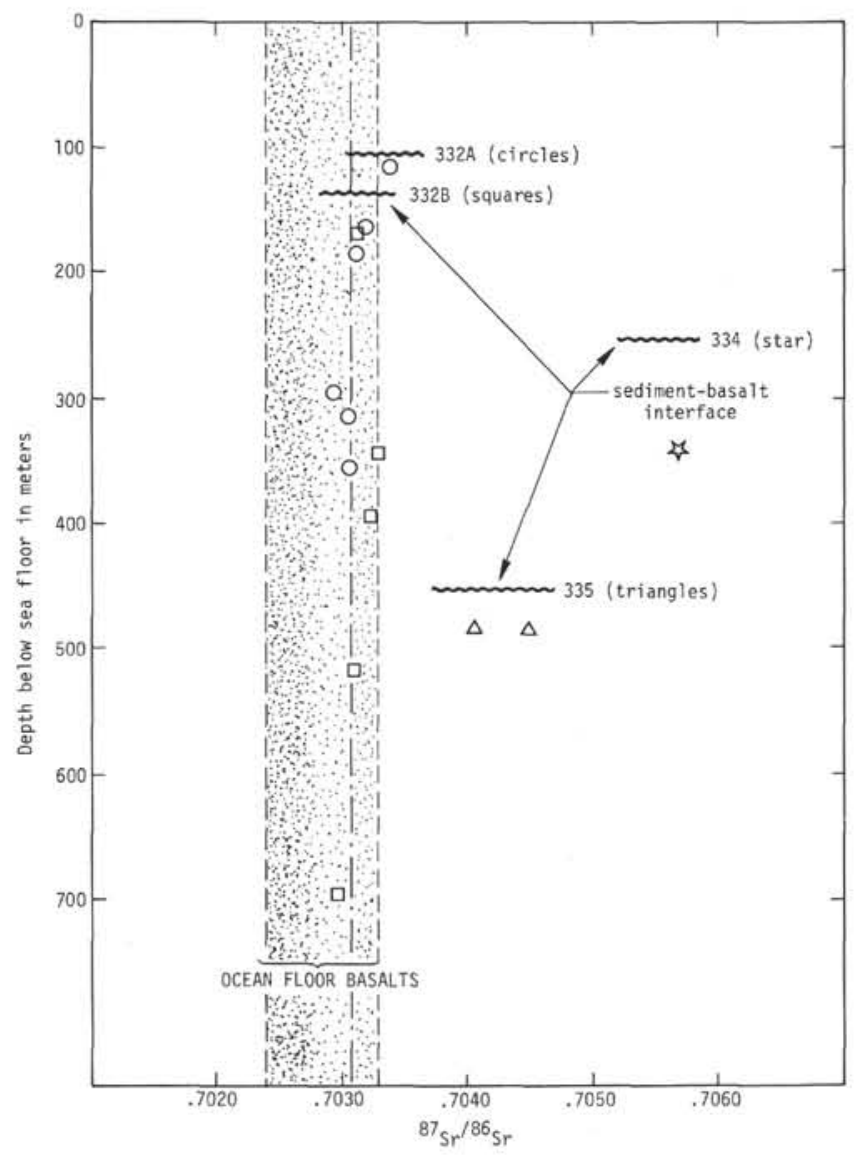

Figure 1. Isotopic composition of strontium from igneous rocks of DSDP Leg 37, as a function of depth in meters below the sea floor. Circles indicate Hole 332A, squares indicate Hole 332B, the star indicates Site 334, and triangles indicate Site 335.

by Bonatti et al. (1970), Melson et al. (1972), and Subbarao et al. (1973) for samples of similar material. Isotopic and concentration data for large numbers of samples, when combined with age information, will provide a quantitative measure of the $\mathrm{Sr}$ exchange between seawater and ocean floor and thus improve our understanding of the geochemical cycle of Sr.

The measured lead isotopic compositions for 14 samples are shown in Figures 2 and 3 and in Table 1. Data are not adjusted in any way. For five samples, double spiking measurements were completed. These gave reliable concentrations for lead (cf. Table 1), but unreliable estimates for discrimination. Apparent (unrealistic) discriminations up to $2.2 \%$ per unit mass could not be attributed to mass spectrometer error, but seem to reflect a failure of the basic assumptions of double spiking. We suspect that the difficulty may be the presence of a non-neglible blank.

On Figures 2 and 3 are shown the primary lead growth curve of Cooper et al. (1969) and the north/east Atlantic sediment lead composition of Chow and Patterson (1962). The new analyses tend to lie below and beyond the growth curves, a known characteristic of oceanic basalts (Russell, 1972). For the samples from Holes $332 \mathrm{~A}$ and $332 \mathrm{~B}$, there is evidence of mixing with

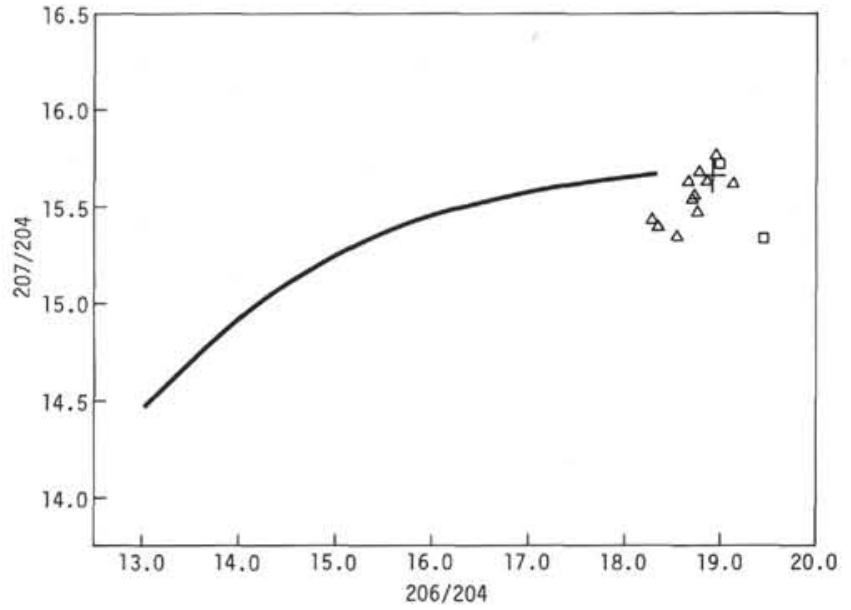

Figure 2. Isotopic composition of lead from igneous rocks of DSDP Leg 37. Triangles indicate Holes $332 \mathrm{~A}$ and $332 B$, and circles indicate Sites 334 and 335 . The cross shows the mean isotopic composition of sediments from the north-east Atlantic (Chow and Patterson, 1962, adjusted approximately to absolute values as in Russell, 1972).

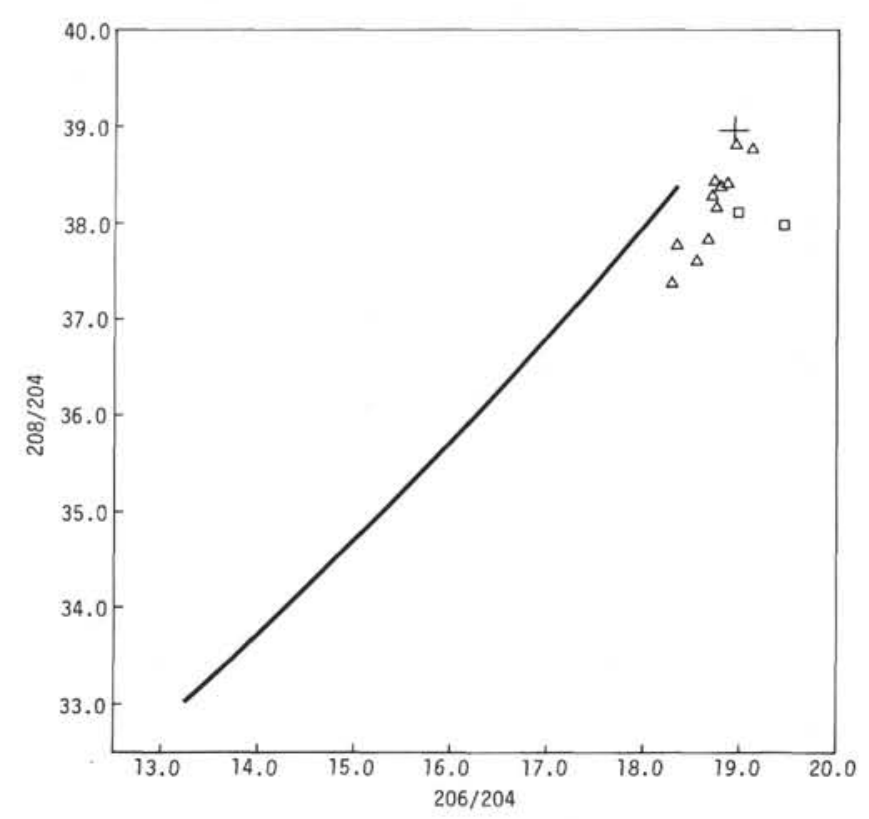

Figure 3. Isotopic composition of lead from igneous rocks for DSDP Leg 37. Triangles indicate Holes $332 \mathrm{~A}$ and $332 B$, and circles indicate Sites 334 and 335. The cross shows the mean isotopic composition of sediments from the northeast Atlantic (Chow and Patterson, 1962, adjusted approximately to absolute values as in Russell, 1972).

lead of composition similar to that in the pelagic sediments.

\section{CONCLUSIONS}

The freshest igneous rocks found in Holes $332 \mathrm{~A}$ and 332 $\mathrm{B}$ are somewhat enriched in radiogenic $\mathrm{Sr}$ and $\mathrm{Pb}$ when compared to average ocean floor basalt (Tat- 
TABLE 1

Measured Lead and Strontium Isotopic Composition for 14 Samples

\begin{tabular}{|c|c|c|c|c|c|c|c|c|}
\hline \multirow{2}{*}{$\begin{array}{c}\text { Sample } \\
\text { (Interval in } \mathrm{cm})\end{array}$} & \multirow{2}{*}{$\begin{array}{l}\text { Piece } \\
\text { No. }\end{array}$} & \multicolumn{4}{|c|}{ Isotopic Composition } & \multicolumn{3}{|c|}{$\begin{array}{c}\text { Chemical } \\
\text { Compositions (ppm) }\end{array}$} \\
\hline & & $206 / 204$ & $207 / 204$ & $208 / 204$ & $87 / 86(1 \sigma)$ & $\mathrm{Pb}$ & $\mathrm{Rb}$ & $\mathrm{Sr}$ \\
\hline \multicolumn{9}{|l|}{ Hole 332A } \\
\hline $\begin{array}{l}7-2,15-17 \\
12-1,123 \\
14-1,127-129 \\
26-1,43-45 \\
28-2,57-59 \\
32-1,106-108\end{array}$ & $\begin{array}{l}19 \\
12 \mathrm{D} \\
12 \\
2 \\
9 \\
14 \mathrm{~B}\end{array}$ & $\begin{array}{l}18.86 \\
18.72 \\
18.66 \\
19.13 \\
18.70 \\
18.35\end{array}$ & $\begin{array}{l}15.67 \\
15.57 \\
15.65 \\
15.63 \\
15.55 \\
15.41\end{array}$ & $\begin{array}{l}38.42 \\
38.45 \\
37.85 \\
38.78 \\
38.31 \\
37.78\end{array}$ & $\begin{array}{l}0.70339(6) \\
0.70318(6) \\
0.70310(4) \\
0.70293(4) \\
0.70304(4) \\
0.70304(7)\end{array}$ & 0.59 & $\begin{array}{l}6 \\
2 \\
8 \\
7 \\
4 \\
3\end{array}$ & $\begin{array}{l}125 \\
111 \\
125 \\
117 \\
121 \\
114\end{array}$ \\
\hline \multicolumn{9}{|l|}{ Hole 332B } \\
\hline $\begin{array}{l}2-5,103-106 \\
9-3,14-16 \\
14-1,33-35 \\
27-2,56-58 \\
46-3,36-38\end{array}$ & $\begin{array}{l}10 \\
3 \\
1 \\
6 \\
3 \mathrm{~A}\end{array}$ & $\begin{array}{l}18.75 \\
18.78 \\
18.95 \\
18.29 \\
18.54\end{array}$ & $\begin{array}{l}15.49 \\
15.68 \\
15.78 \\
15.44 \\
15.35\end{array}$ & $\begin{array}{l}38.18 \\
38.39 \\
38.83 \\
37.40 \\
37.61\end{array}$ & $\begin{array}{l}0.70310(3) \\
0.70329(4) \\
0.70320(3) \\
0.70308(4) \\
0.70294(5)\end{array}$ & $\begin{array}{l}0.95 \\
0.75 \\
0.74 \\
1.31\end{array}$ & $\begin{array}{l}1 \\
5 \\
3 \\
3 \\
2\end{array}$ & $\begin{array}{r}97 \\
118 \\
117 \\
118 \\
113\end{array}$ \\
\hline \multicolumn{9}{|l|}{ Site 334} \\
\hline $24-3,136-140$ & 12 & 18.98 & 15.72 & 38.10 & $0.70565(10)$ & & 0 & 7 \\
\hline \multicolumn{9}{|l|}{ Site 335} \\
\hline $\begin{array}{l}8-3,61-63 \\
8-3,61-63\end{array}$ & $\begin{array}{l}5 \mathrm{~B}-\mathrm{I} \\
5 \mathrm{~B}-\mathrm{II}\end{array}$ & $\begin{array}{l}18.51 \\
19.44\end{array}$ & $\begin{array}{l}15.35 \\
15.34\end{array}$ & $\begin{array}{l}37.86 \\
37.97\end{array}$ & $\begin{array}{l}0.70402(6) \\
0.70447(4)\end{array}$ & & $\begin{array}{r}7 \\
13\end{array}$ & $\begin{array}{r}95 \\
100\end{array}$ \\
\hline
\end{tabular}

sumoto, 1966; Sun, 1973; and references already cited), and they are comfortably within the isotope space occupied by oceanic volcanic rocks (ocean floor and islands). On a variety of plots (not illustrated) they lie at the radiogenic end of the ocean floor basalt data cluster, within the ocean island spectrum, and they are distinctly separate from the rocks of any volcanic arc region. With respect to $\mathrm{Sr}$ and $\mathrm{Pb}$ the rocks of this area of the sea floor are remarkably like the basalts of Iceland and the Reykjanes Ridge (Welke et al., 1968; Hart et al., 1973; O'Nions and Gronvöld, 1973). For Holes $332 \mathrm{~A}$ and 332B there appears to be a weak correlation between the ratio ${ }^{206} \mathrm{~Pb} /{ }^{204} \mathrm{~Pb}$ and ${ }^{87} \mathrm{Sr} /{ }^{86} \mathrm{Sr}$.

\section{ACKNOWLEDGMENTS}

This research was supported by the National Research Council of Canada by special Grant DAG-6. Facilities for the research are financed by Grants A720, A131, A8841, and E3551, also from the National Research Council. Support of scientists from Dalhousie University and the University of Alberta is acknowledged with thanks. M. Yamaguchi wishes to thank Kyushu University for arranging leave so that he could participate in this study, and to thank the University of British Columbia for its hospitality.

\section{REFERENCES}

Bonatti, E., Honnorez, J., and Ferrara, G., 1970. Equatorial Mid-Atlantic Ridge: Petrologic and $\mathrm{Sr}$ isotopic evidence for an alpine-type rock assemblage: Earth Planet. Sci. Lett., v. 9, p. 247-256.

Chow, T.J. and Patterson, C.C., 1962. The occurrence and significance of lead isotopes in pelagic sediments: Geochim. Cosmochim. Acta, v. 26, p. 263-308.

Cooper, J.A., Reynolds, P.H., and Richards, J.H., 1969. Double spike calibration of the Broken Hill standard lead: Earth Planet. Sci. Lett., v. 6, p. 467-478.
Dasch, E.J., Hedge, C.E., and Dymond, J., 1973. Effect of sea water interaction on strontium isotope composition of deep sea basalt: Earth Planet. Sci. Lett., v. 19, p. 177-183.

Hart, S.R., 1972. Sr isotopic composition of the oceanic crust: Carn. Inst. Wash. Yearbook 71, p. 288-292.

1973. A model for chemical exchange in the basaltsea water system of oceanic layer II: Canadian J. Earth Sci., v. 10, p. $799-816$.

Hart, S.R. and Nalwalk, A.J., 1970. K, Rb, and $\mathrm{Sr}$ relationships in submarine basalts from the Puerto Rico trench: Geochim. Cosmochim. Acta., v. 34, p. 145-155.

Hart, S.R., Schilling, J.G., and Powell, J.L., 1973. Basalts from Iceland and along the Reykjanes ridge: $\mathrm{Sr}$ isotope geochemistry: Nature, v. 246, p. 104-107.

Hedge, C.E. and Peterman, Z.E., 1970. The strontium isotopic composition of basalts from the Gordo and Juan de Fuca rises, northeastern Pacific Ocean: Contrib. Mineral. Petrol., v. 27, p. 114-120.

Krogh, T.E., 1973. A low-contamination method for hydrothermal decomposition of zircon and extraction of $U$ and $\mathrm{Pb}$ for isotopic age determinations: Geochim. Cosmochim. Acta, v. 37, p. 485-494.

Mattinson, J.M., 1972. Preparation of hydrofluoric, hydrochloric and nitric acids at ultralow lead levels: Anal. Chem., v. 44, p. 1715-1716.

Melson, W.G., Hart, S.R., and Thompson, G., 1972. St. Paul's rocks, equatorial Atlantic: petrogenesis, radiometric ages, and implications on sea-floor spreading: Geol. Soc. Am. Mem., v. 132, p. 241-272.

O'Nions, R.K. and Gronvöld, K., 1973. Petrogenetic relationships of acid and basic rocks in Iceland: $\mathrm{Sr}$ isotopes and rare-earth elements in late and post glacial volcanics: Earth Planet. Sci. Lett., v. 19, p. 397-409.

Peterman, Z.E. and Hedge, C.E., 1971. Related strontium isotopic and chemical variations in oceanic basalts: Geol. Soc. Am. Bull., v. 82, p. 493-500.

Russell, R.D., 1972. Evolutionary model for lead isotopes in conformable ores and in ocean volcanics: Rev. Geophys. Space Phys., v. 10, p. 529-549. 
Subbarao, K.V., 1972. The strontium isotopic composition of basalts from the East Pacific and Chile rises and abyssal hills in the eastern Pacific Ocean: Contrib. Mineral. Petrol., v. 37, p. 111-120.

Subbarao, K.V. and Hedge, C.E., 1973. K, Rb, Sr and ${ }^{87} \mathrm{Sr} /{ }^{86} \mathrm{Sr}$ in rocks from the mid-Indian Oceanic ridge: Earth Planet. Sci. Lett., v. 18, p. 223-228.

Sun, S.S., 1973. Lead isotopic studies of young volcanic rocks from oceanic islands, mid-ocean ridges and island arcs: Ph.D. Thesis, Columbia University.
Tatsumoto, M., 1966. Genetic relations of oceanic basalts as indicated by lead isotopes: Science, v. 153, p. 1094-1101. Tatsumoto, M., Hedge, C.E., and Engel, A.E.J., 1965. Potassium, rubidium, strontium, thorium, uranium and the ratio of strontium- 87 to strontium- 86 in oceanic tholeiitic basalt: Science, v. 150 , p. $886-888$.

Welke, H., Moorbath, S., and Cumming, G.L., 1968. Lead isotope studies on igneous rocks from Iceland: Earth Planet. Sci. Lett., v. 4, p. 221-231. 